\title{
Men's first partnership formation in four former state-socialist countries during the transition period
}

\author{
by Cornelia Mureşan* and Livia Sz. Oláh**
}

\begin{abstract}
Non-marital cohabitation has become increasingly common in advanced societies, although somewhat less so in Central-Eastern Europe in the period immediately following the fall of state socialism. In this paper we focus on changes in men's first partnership patterns in Bulgaria, Hungary, Poland and Romania between the 1980s and early 2000s, specifically addressing gender differences with respect to the effects of educational attainment. Data on men and women extracted from the first round of Generations and Gender Programme in these countries are analysed, relying on proportional hazards event history models with piecewise constant baseline intensity for entering a first union (cohabitation or direct marriage - as competing risks). We find a positive educational gradient for marriage formation among men in all countries analysed, but only in Hungary for women. No such gradient is seen for cohabitation among men with the exception of Poland. The popularity of cohabitation increased over time while the trend for marriage entry declined, resulting in non-marital unions replacing marriage as the main form of first partnerships by the late 1990s-early 2000s, except for Romania. Declining marriage trends paralleled by women’s growing educational advantage are likely to be related to the limited (and decreasing) supply of highly educated men as most attractive marriage partners in the region. The main contribution of this study is to fill the knowledge gap on changes in family formation patterns with emphasis on men's first co-residential unions in Central-Eastern Europe in the period of major societal transition. The results point to the importance of gendered effects of educational attainment with respect to the type of first union formed.
\end{abstract}

\section{Keywords}

first union, marriage, cohabitation, educational attainment, Generations and Gender Survey, Bulgaria, Hungary, Poland, Romania.

* Babeş-Bolyai University, Faculty of Sociology and Social Work, 128, 21 Decembrie 1989 Bvd, Cluj-Napoca, Romania, cornelia.muresan@socasis.ubbcluj.ro

** Stockholm University, Department of Sociology, Universitetsvägen 10B, 11418 Stockholm, Sweden, livia.olah@sociology.su.se 


\section{Rationale}

The supremacy of marriage has weakened substantially in Europe since the late 1960s. Marriage propensities decreased first in Scandinavia, followed by Western Europe and Anglosaxon countries, and more recently by Southern Europe (Sobotka, and Toulemon, 2008). In parallel, the mean age at first marriage increased, reaching ages of late twentiesearly thirties in the 2000s. High marriage rates prevailed in Central-Eastern Europe up until the early 1990s, when a rapid decline took place, followed by a levelling off, and a moderate increase in recent years. However, early marriages prevailed there until the end of the $20^{\text {th }}$ century, when the mean age at marriage increased steeply, to age 28-29 in recent years. In all Europe, men have entered marriage at even higher ages than women (Council of Europe, 2004; Eurostat 2019). Delayed marriage does not necessarily mean that young people refrain from couple relationships. In fact, the prevalence of non-marital cohabitation has increased across Europe (Perelli-Harris and Lyons-Amos, 2015). In the Central-Eastern region cohabitation is still quite rare in some societies (particularly Poland, Slovakia and the Czech Republic), but less so in other countries (Kasearu MA and Kutsar 2011). The choice between consensual union and direct marriage as first partnership is likely to be related to educational attainment, as highlighted in previous research (Kalmijn 2013; Perelli-Harris and LyonsAmos, 2016). Also, the effect of education may differ for women and men (see e.g. Becker 1991; Oppenheimer 1988, 1997, 2003).

This study seeks to provide a better understanding of changes in especially men's partnership formation patterns in the former state-socialist countries focusing on the period from the 1980s to the early 2000s when the transition to a market economy took place (see also Philipov and Dorbritz, 2003). High marriage rates until the early 1990s notwithstanding, there were variations across Central-East European countries with respect to cohabitation becoming 
a viable option at first union formation (Hoem et al. 2009a,b; Puur et al. 2012). However, we know relatively little about men with respect to changes in family patterns as previous studies have mainly focused on women (but see Katus et al. 2007 on Baltic countries, as exception). We intend to fill the gap and address changes in first co-residential living arrangements, with emphasis on men, in four countries in the region in the period of major societal transition.

\section{Data and methods}

\subsection{Data}

In this study on first union formation, we consider non-marital cohabitation as a competitor to conventional marriage. We did not include LAT relationships, neither partnerships which lasted for less than three months, the latter not being considered a "union" in GGS. We analyze data extracted from the first round of the Gender and Generations Surveys (GGS) for four countries in Central-Eastern Europe: Bulgaria, Hungary, Poland and Romania. A random sample of women and men aged 18-79 years were interviewed in each country. In our analyses, we rely on country subsamples of persons of relevant ages for partnership formation in 1980-2004/05. Our subsample contains unpartnered men and women who were in the agerange 15- 40 years in the period of interest given early partnership patterns in the region. See Table 1 for information on when the surveys were conducted, the country subsample sizes and the distribution of respondents by union type in the period of interest. 
Table 1. National sub-sample sizes, number of events and percent distribution of events by union type

\begin{tabular}{|c|c|c|c|c|}
\hline & $\begin{array}{c}\text { Sample } \\
\text { size }\end{array}$ & $\begin{array}{c}\text { Number } \\
\text { of } 1 \text { st } \\
\text { unions }\end{array}$ & $\begin{array}{c}\text { Percent } \\
\text { cohabitations }\end{array}$ & $\begin{array}{c}\text { Percent } \\
\text { direct } \\
\text { marriages }\end{array}$ \\
\hline \multicolumn{5}{|c|}{ Bulgaria (interview date: Oct-Dec 2004) } \\
\hline men & 3644 & 2129 & $66 \%$ & $34 \%$ \\
\hline women & 4423 & 3156 & $66 \%$ & $34 \%$ \\
\hline \multicolumn{5}{|c|}{ Hungary (interview date: Nov 2004-May 2005) } \\
\hline men & 3539 & 2101 & $42 \%$ & $58 \%$ \\
\hline women & 3516 & 2504 & $38 \%$ & $62 \%$ \\
\hline \multicolumn{5}{|c|}{ Poland (interview date: Jan 2010-Dec 2011) } \\
\hline men & 5173 & 2995 & $26 \%$ & $74 \%$ \\
\hline women & 6070 & 4024 & $26 \%$ & $74 \%$ \\
\hline \multicolumn{5}{|c|}{ Romania (interview date: Nov-Dec 2005) } \\
\hline men & 3354 & 2371 & $25 \%$ & $75 \%$ \\
\hline women & 2679 & 2176 & $27 \%$ & $73 \%$ \\
\hline
\end{tabular}

We seek to gain better insight in whether and how the major societal transformation, that is, the fall of state-socialism (dated to late 1989-early 1990) influenced first partnership formation patterns in the countries studied. We analyze the entrance into first union between January 1980 and the end of 2005 (or somewhat earlier, depending on the date of interview). All individuals aged 15-40 during the period of interest (1980-2004/05), without previous coresidential partnership experience were included in our working-sample. The vast majority formed a first union, but the proportions in a particular type of partnership varied across countries. With focus on the entire period, only Bulgarians are seen to display a clear preference for cohabitation (66\%) compared to direct marriage, whereas the percentages of marital unions are higher than those of cohabitations in the other three countries (Table 1).

\subsection{Method and covariates}

Intensity regression is our analytical tool. We study entries into marriage and to a non-marital union jointly as competing risks in a manner that permits direct comparison between the two types of union formation in each country and for each sex (the same way as Hoem et al. 
2009a). Based on data in a monthly format for the years 1980-2005, proportional-hazards event-history models with piecewise constant baseline intensity are applied. In different steps, we interacted the union type with age-group, calendar period, pregnancy and parity status, educational attainment (all time-varying covariates; see Appendix). Additionally, we fit a simple (i.e. not competing risks) proportional-hazard model to illuminate general effects of considered determinats on first union formation.

We divided age into five-year age-groups, and the period between 1980 and 2004/5 into fiveyear periods in which the risks to form a union is considered constant but (may) vary across intervals. As for pregnancy-and-parity status, we differentiate between (i) childless nonpregnant, (ii) childless pregnant, and (iii) parent (fathers / mothers at parities 1 and above). For male respondents, the pregnancy status applies to the partner. Information on pregnancy is derived from the children's birthdates reported by the respondents. We consider a nonpartnered respondent childless and non-pregnant if the first child (if any) was born at least 7 months after the date of first union formation. If the first child was born after the formation of first union, but within 7 months of that date, the respondent is considered childless pregnant. Parents are respondents who have at least one child born before the formation of their first union.

The effect of educational attainment for first union formation is of key interest for this study, even if we do not have exhaustive information for a genuine time-varying covariate. We have information on the respondents' highest level of education at the interview, and on the date that level of education was aquired (according to respondents' own reports). Hence we have had to impute information for a non-fixed covariate relying on a method developed by Hoem and Kreyenfeld (2006). As we aim to shed more light on the changing trends in union 
formation, we display below the interactions between union type and each of the covariates of interest, separately by sex and country, without showing the relative risks for the other covariates controlled for in the models.

\section{Results}

\subsection{Trends over the years $1980-2005$}

First, we study trends in first union formation for childless male respondents whose partner is not expecting a child, and for childless non-pregnant female respondents (Figure 1). The group of childless non-pregnant dominates the exposures to the risk of first-union formation (see Appendix), hence we report these results for this group alone.

For Bulgaria, we see stable trends for marriage and cohabitation, with slight preference for non-marital unions among both men and women throughout the period. For the other three countries in contrast, the trends clearly indicate declining intensity for marriage formation and increasing intensity for cohabitation, but marriage remains the dominant partnership type for most of the period. Among Hungarian men (and women), cohabitation has overcome marriage in popularity from the mid-1990s onwards. Similar change of preference appears among Polish men (and women) in the early 2000s, but not quite in Romania despite diminishing differences in the relative risks for these union types from the early-/mid 1990s, onwards. 
Figure 1. Relative risks of union formation for nulliparous men and women not expecting a child, by calendar-period and union type
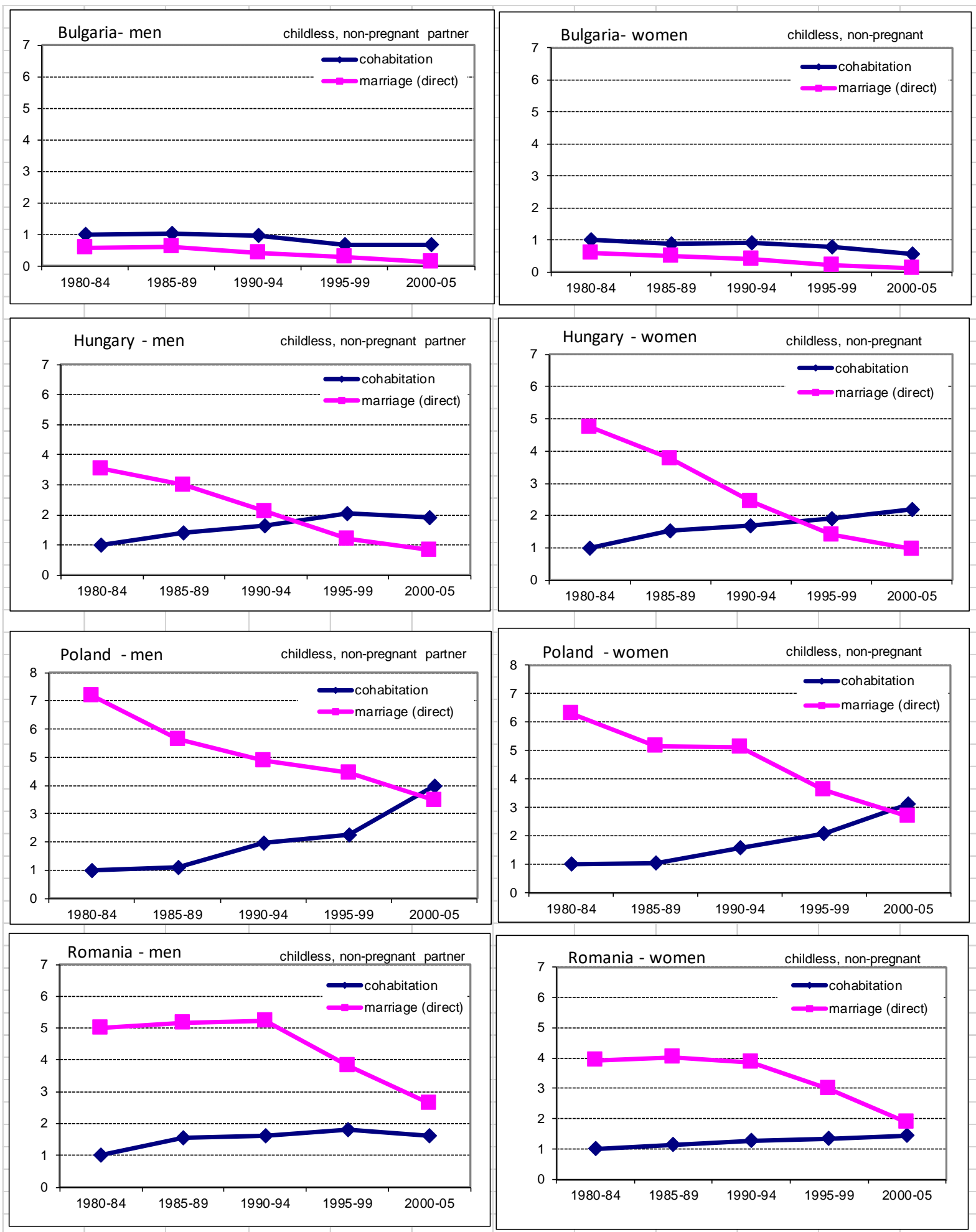

Note: All the models above control for age group and education. 


\subsection{Age profiles}

As a second step in our analysis, we address the role of age on the choice of union type. As Figure 2 shows, age matters. For very young men, that is, below age twenty, we do not find clear preferences for either cohabitation or marriage, except for Bulgaria with a slight preference for non-marital unions. Also at ages of mid-/late thirties there are relatively limited differences for preferred union type, especially for Hungary, but a slight preference may be seen for marriage at those ages among Polish and Romanian men (and women). For the other age-groups we find pronounced marriage preference for both men and women in Poland and Romania and similar but less substantial preference in Hungary. In contrast, Bulgaria displays clear preference for non-marital cohabitation among both men and women at all ages although the difference compared to marriage nearly disappears in mid-/late thirties (especially for women). In all countries, the highest rates for first union formation are seen for ages of late twenties for men, but the difference compared to ages of early twenties is negligible for cohabitation. For women, we find the highest rates of first union entrance at ages of early twenties, with little difference to ages of late twenties regarding cohabitation, except for Bulgaria. Thus the findings suggest sharper contrasts for the age profile for marriage than for consensual unions for both sexes in these four countries. 
Figure 2. Absolute risk of entry into first union by age group and union type (number of unions per 1000 person-years)
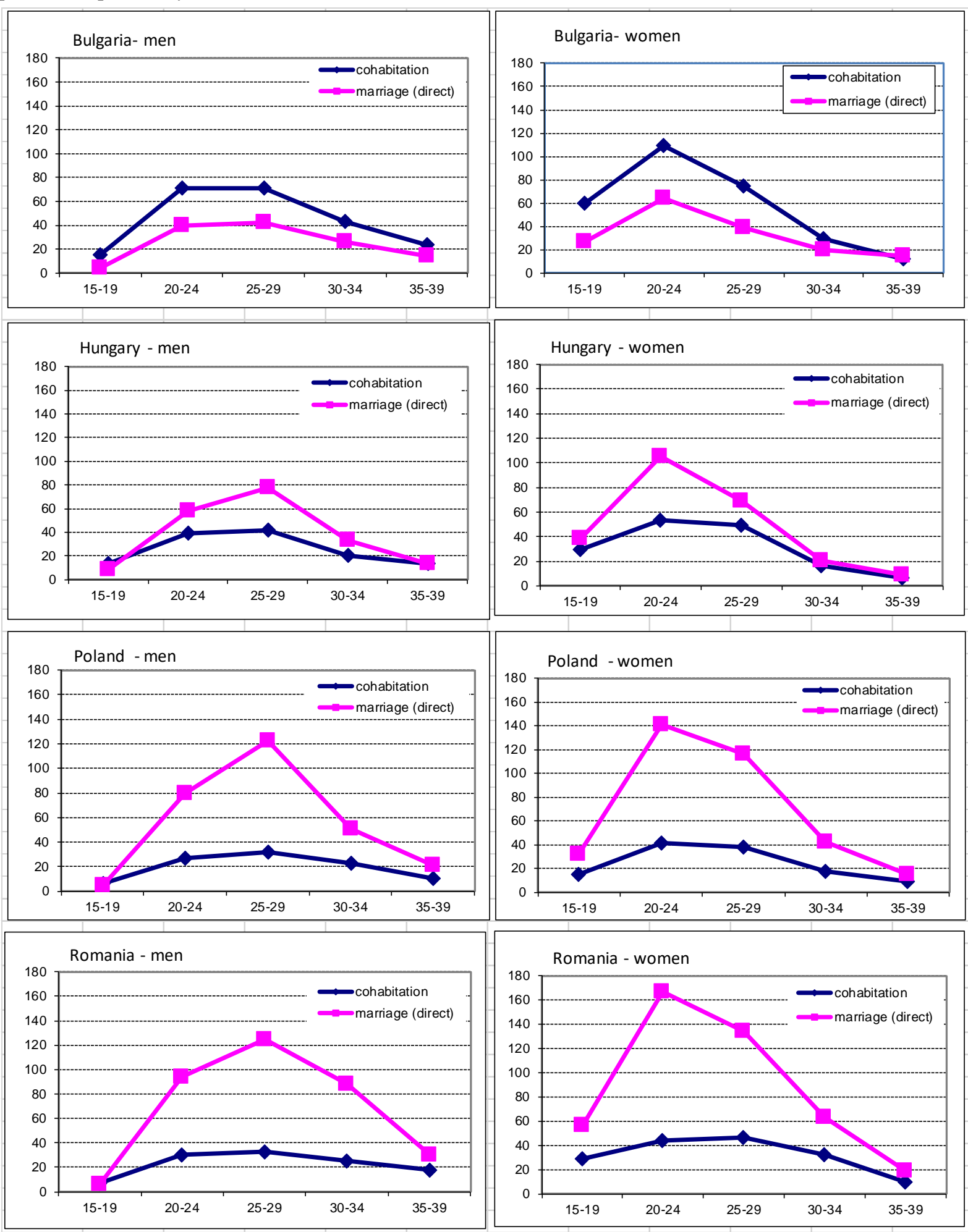

Note: All the models above control for calendar-period, parity-pregnancy status and education. 


\subsection{Gender differences in the effects of educational attainment}

Next, we address the effects of educational attainment. As Table 2 shows, pregnancy speeds up first-union formation, but pre-union parenthood diminishes the intensity among women (except for Poland), and increases the intensity among men (except in Hungary). While no big differences are shown for calendar periods, we see a diminishing trend for the formation of first co-residential relationships in all countries from the early- or mid-1990s, onwards, and more so in the early 2000s, except for Poland. Educational differences are more pronounced, with students having the lowest propensity to start a first union. A positive educational gradient is seen for Hungary for both sexes, and for men in Poland and Romania.

Table 2. Transition to first union, results of hazard regressions

\begin{tabular}{|crrrr|}
\hline \hline \multicolumn{5}{c}{ Men } \\
Bulgaria & Hungary & Poland & Romania \\
\hline \hline Age (absolute risks per 1000 person-years) & & \\
$15-19$ & 18.95 & 15.20 & 3.62 & 4.62 \\
$20-24$ & 84.42 & 50.41 & 24.69 & 32.50 \\
$25-29$ & 82.41 & 55.26 & 31.81 & 37.10 \\
$30-34$ & 82.41 & 55.26 & 31.81 & 37.10 \\
$35-39$ & 26.19 & 14.86 & 7.64 & 11.43 \\
\hline Union type (relative risks) & & & & \\
cohabitation & 1 & 1 & 1 & 1 \\
marriage (direct) & 0.53 & 1.41 & 2.80 & 2.95 \\
\hline Parity/pregnancy status (relative risks) & & & \\
childless not pregnant p. & 1 & 1 & 1 & 1 \\
childless pregnant p. & 26.90 & 15.59 & 29.58 & 19.30 \\
father & 1.12 & 0.69 & 3.39 & 2.40 \\
\hline Education (relative risks) & \multicolumn{4}{c}{} \\
low & 1.19 & 0.88 & 0.62 & 0.87 \\
high & 1.17 & 1.18 & 1.46 & 1.35 \\
in education & 0.52 & 0.47 & 0.74 & 0.58 \\
\hline Calendar year (relative risks) & 1 & & & \\
$1980-1984$ & 1 & 1 & 1 & 1 \\
$1985-1989$ & 1.07 & 0.97 & 0.95 & 1.12 \\
$1990-1994$ & 0.93 & 0.84 & 0.91 & 1.15 \\
$1995-1999$ & 0.67 & 0.77 & 0.90 & 0.99 \\
$2000-2005$ & 0.57 & 0.64 & 0.95 & 0.76 \\
\hline \hline
\end{tabular}




\begin{tabular}{|cccrr|}
\hline \multicolumn{5}{c}{ Women } \\
Bulgaria & Hungary & Poland & Romania \\
\hline \hline Age (absolute risks per 1000 person-years) \\
$15-19$ & 120.54 & 58.99 & 18.66 & 42.49 \\
$20-24$ & 182.71 & 94.72 & 45.65 & 72.35 \\
$25-29$ & 111.71 & 67.13 & 35.19 & 55.19 \\
$30-34$ & 111.71 & 67.13 & 35.19 & 55.19 \\
$35-39$ & 27.87 & 11.30 & 5.53 & 9.06 \\
\hline Union type (relative risks) & & & & \\
cohabitation & 1 & 1 & 1 & 1 \\
marriage (direct) & 0.52 & 1.60 & 2.86 & 2.73 \\
\hline Parity/pregnancy status (relative risks) & & & \\
childless not pregnant & 1 & 1 & 1 & 1 \\
childless pregnant & 17.23 & 11.34 & 20.72 & 10.94 \\
mother & 0.56 & 0.46 & 1.60 & 0.72 \\
\hline low & 0.97 & 0.83 & 0.87 & 1.05 \\
middle & 1 & 1 & 1 & 1 \\
high & 1.00 & 1.25 & 1.06 & 0.94 \\
Education (relative risks) & 0.36 & 0.33 & 0.47 & 0.27 \\
\hline Calendar year (relative risks) & & & & \\
$1980-1984$ & 1 & 1 & 1 & 1 \\
$1985-1989$ & 0.94 & 0.94 & 0.95 & 1.07 \\
$1990-1994$ & 0.89 & 0.82 & 1.01 & 1.07 \\
$1995-1999$ & 0.70 & 0.65 & 0.96 & 0.92 \\
2000-2005 & 0.47 & 0.62 & 0.95 & 0.80 \\
\hline \hline
\end{tabular}

Note: Relative risks in italic are statistical significants $p<0.05$

We also investigate the impact of educational attainment by partnership type. Figure 3 shows a pronounced positive educational gradient for marriage formation among men in Romania and especially Poland, and a small one in Hungary and Bulgaria. The same gradient appears for cohabiting Polish men, whereas no differences are seen by education for non-marital unions among Hungarian men. In Bulgaria and Romania, men and women with the least education are the most likely to enter cohabitation as first partnership. We find little differences by educational level among women in Hungary and Poland entering cohabitation, but a slightly negative educational gradient appears for their Bulgarian and especially Romanian counterparts. In contrast, there are no educational differences among women entering marriage in Romania. We find a positive educational gradient for marriage formation among women in Hungary, and similar but smaller one in Bulgaria, while an inverted U- 
shape is seen for Polish women with the middle-educated being most likely to enter marriage. In all countries, students have the lowest propensity to form any type of first union among both men and women, except for cohabitation among Polish men. 
Figure 3. Relative risk of union formation by educational attainment and union type
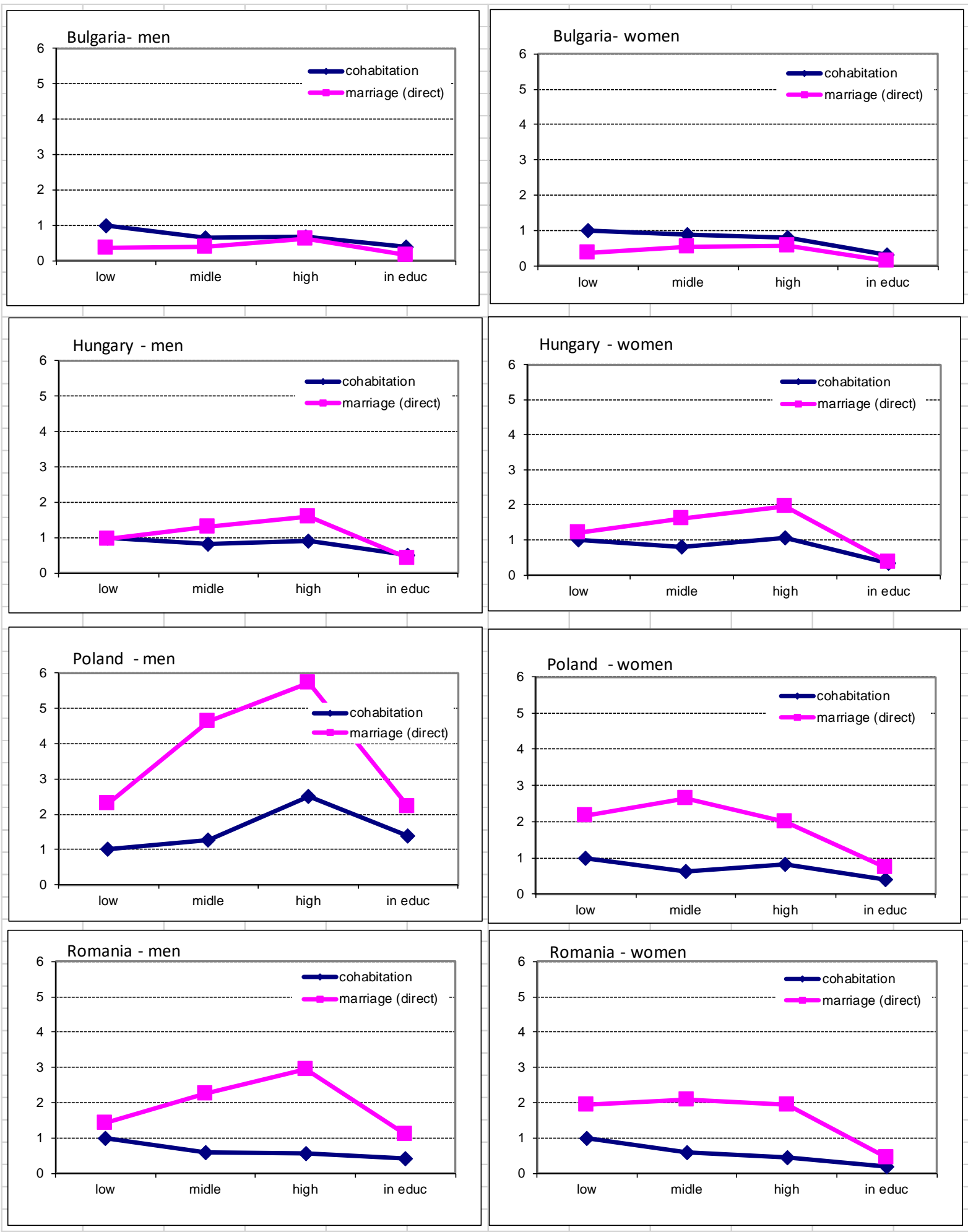

Note: All the models above control for calendar-period, age group, and parity-pregnancy status. 


\section{Discussion}

In this study we have addressed men's first partnership patterns in selected countries in Central-Eastern Europe, with main focus on the transition period. Based on data of the Gender and Generations Surveys we have analyzed trends, age-profiles and gender differences in the effects of educational attainment on entering non-marital cohabitation versus direct marriage, that is marrying without cohabiting with the partner first. Despite similarities in the political and economic contexts, distinct country-specific patterns have been noted with respect to first union formation. In Bulgaria, we have seen somewhat higher propensity to enter cohabiting relationships compared to marriages from the early 1980s, and this preference has not changed. In Hungary, a preference for direct marriage has characterized the 1980s, but from the mid-1990s onwards, first partnerships have been more likely to be cohabiting relationships than marriages there. Direct marriage has remained the main type of first partnerships in Poland and Romania although its popularity declined in the 1990s. By the early 2000s, it has become slightly more common in Poland to choose cohabitation instead of marriage as first union. In Romania however, preference for cohabitation increased only slightly even in the late 1990s-early 2000s, hence marriage intensity remained higher than that of entering cohabitation throughout the period.

Regarding gender differences in the age profile by first union type, the propensity to enter marriage has varied much more by age than that for cohabiting unions in three of the four countries with Bulgaria exhibiting larger variations for cohabiting relationships. The peak of first marriage formation has been at ages of late twenties for men, and early twenties for women, with limited differences between the intensities for cohabitation at these peak ages for both sexes. Gender differences also appear for educational attainment. Men with higher education have been the most likely to marry in all four countries, with pronounced 
differences in Poland and Romania, but small differences in Hungary and especially in Bulgaria. For women in contrast, we have found no educational variations for marriage entry in Romania, little differences between middle and highly educated women’s marriage propensities in Bulgaria, the highest marriage propensity for the middle educated in Poland, and a positive educational gradient for marriage in Hungary. The patterns have been quite different for cohabiting relationships. In Bulgaria and Romania, the least educated men and women have had the highest propensity to enter non-marital unions. In Hungary, the low- and the highly educated among both men and women have been equally likely to form cohabiting relationship, while the middle educated have had lower propensity. Among Polish men we have seen a positive educational gradient also for cohabitation, whereas among women the highly educated have been only slightly less likely to enter cohabitation than the least educated, with the lowest propensity seen for the middle educated.

Based on the patterns regarding the effects of educational attainment, the declining trend of marriage formation for all four countries may be related to highly educated men being the most attractive at the marriage market, whereas among women positive educational gradient has been noted only for Hungary. As women's educational attainment compared to their male counterparts has increased across Europe from the 1990s onwards, the gendered pattern with respect to education may have increased the demand for highly educated male marriage partners more than their supply, suppressing marriage formation in these four countries. Given differences in the effects of educational attainment for cohabiting unions versus marriages, the trend to enter cohabitation has increased at the same time. Thus non-marital unions have replaced marriage as the main form of first partnerships in these countries except for Romania, but even there the propensity of marriage formation is only slightly above that of cohabitation in the early 2000s. 
Acknowledgement: The research leading to these results has received funding from the European Union's Seventh Framework Programme (FP7/2007-2013) under grant agreement no. 320116 for the research project FamiliesAndSocieties. Also, financial support to Livia Olah via the Swedish Research Council grant to the Linneaus Center on Social Policy and Family Dynamics in Europe, SPaDE (grant number 349-2007-8701) is gratefully acknowledged. 


\section{References}

BECKER Gary, 1991, A Treatise on the Family. Cambridge, MA: Harvard University Press.

COUNCIL OF EUROPE, 2004, Recent Demographic Developments in Europe. Strasbourg: Council of Europe Publishing.

EUROSTAT, 2019, Populations and social conditions database: Demography and migration: Marriages and divorces: Marriage indicators: Total first marriage rates - females, males; Mean age at first marriage - females, males (accessed 21 March 2019). https://ec.europa.eu/eurostat/data/database; http://appsso.eurostat.ec.europa.eu/nui/show.do?dataset=demo_nind\&lang=en

HOEM Jan Michael, KREYENFELD Michaela, 2006, „Anticipatory analysis and its alternatives in life-course research. Part 2: Marriage and first birth. Reflexions”, Demographic Research, 15(17), pp. 485-498.

HOEM Jan Michael, KOSTOVA Dora, JASILIONIENE Aiva, MUREŞAN Cornelia, 2009a, „Traces of the Second Demographic Transition in Four Selected Countries in Central and Eastern Europe: Union Formation as a Demographic Manifestation”, European Journal of Population, 25, pp. 239-255.

HOEM Jan Michael, KOSTOVA Dora, JASILIONIENE Aiva, MUREŞAN Cornelia, 2009b, „The structure of recent first-union formation in Romania”, Romanian Journal of Population Studies, III(1), pp. 33-44.

KALMIJN Matthijs, 2013, „The educational gradient in marriage: A comparison of 25 European countries”, Demography, 50(4), pp.1499-520.

KASEARU MA Kairi, KUTSAR Dagmar, 2011, "Patterns behind unmarried cohabitation trends in Europe”, European Societies, 13(2), pp. 307-325.

KATUS Kalev, PÕLDMA Asta, PUUR Allan, SAKKEUS Luule, 2007, „First Union Formation in Estonia, Latvia and Lithuania: Patterns across Countries and Gender”, Demographic Research, 17(10), pp. 247-300.

OPPENHEIMER Valerie Kincade, 1988, „A Theory of Marriage Timing”, American Journal of Sociology, 94(3), pp. 563-91.

OPPENHEIMER Valerie Kincade, 1997, „Women's Employment and the Gain to Marriage: The Specialization and Trading Model”, Annual Review of Sociology, 23, pp. 431-53.

OPPENHEIMER Valerie Kincade, 2003, „Cohabiting and Marriage during Young Men’s Career-Development Process”, Demography, 40(1), pp.127-49.

PERELLI-HARRIS Brienna, LYONS-AMOS Mark, 2015, „Changes in partnership patterns across the life course: An examination of 14 countries in Europe and the United States”, Demographic Research, 33(6), pp. 145-178.

PERELLI-HARRIS Brienna, LYONS-AMOS Mark, 2016, „Partnership Patterns in the United States and across Europe: The role of education and Country Context”,Social Forces, 95(1), pp. 251-281.

PHILIPOV Dimiter, DORBRITZ Jurgen, 2003, Demographic Consequences of Economic Transition in Countries of Central and Eastern Europe, Population Studies, 39, Council of Europe Publishing.

SOBOTKA Tomas, TOULEMON Laurent, 2008, „Overview Chapter 4: Changing family and partnership behaviour: Common trends and persistent diversity across Europe”, Demographic Research, 19(6), pp. 85-138. 
Appendix. Exposure time (person-months) and percent distribution by covariates

\begin{tabular}{|c|c|c|c|c|}
\hline & \multicolumn{3}{|c|}{ Men } & \multirow[b]{2}{*}{ Romania } \\
\hline & Bulgaria & Hungary & Poland & \\
\hline Person-months & 32264 & 33086 & 43544 & 29227 \\
\hline \multicolumn{5}{|l|}{$\%$ by calendar period } \\
\hline 1980-1984 & $17 \%$ & $17 \%$ & $18 \%$ & $20 \%$ \\
\hline 1985-1989 & $19 \%$ & $18 \%$ & $18 \%$ & $23 \%$ \\
\hline 1990-1994 & $20 \%$ & $21 \%$ & $19 \%$ & $21 \%$ \\
\hline 1995-1999 & $22 \%$ & $24 \%$ & $20 \%$ & $18 \%$ \\
\hline 2000-2005 & $22 \%$ & $20 \%$ & $24 \%$ & $18 \%$ \\
\hline \multicolumn{5}{|l|}{$\%$ by age group } \\
\hline $15-19$ & $43 \%$ & $39 \%$ & $40 \%$ & $40 \%$ \\
\hline $20-24$ & $32 \%$ & $32 \%$ & $32 \%$ & $33 \%$ \\
\hline $25-29$ & $14 \%$ & $15 \%$ & $15 \%$ & $15 \%$ \\
\hline $30-34$ & $7 \%$ & $8 \%$ & $8 \%$ & $7 \%$ \\
\hline $35-39$ & $4 \%$ & $6 \%$ & $6 \%$ & $4 \%$ \\
\hline \multicolumn{5}{|c|}{$\%$ by parity/pregnancy status } \\
\hline childless not pregnant $p$. & $98 \%$ & $92 \%$ & $97 \%$ & $85 \%$ \\
\hline childless pregnant $p$. & $0.3 \%$ & $0.6 \%$ & $0.7 \%$ & $2.9 \%$ \\
\hline father & $2 \%$ & $7 \%$ & $2 \%$ & $12 \%$ \\
\hline \multicolumn{5}{|l|}{$\%$ by education } \\
\hline Iow & $17 \%$ & $12 \%$ & $11 \%$ & $19 \%$ \\
\hline middle & $43 \%$ & $48 \%$ & $42 \%$ & $43 \%$ \\
\hline high & $5 \%$ & $6 \%$ & $3 \%$ & $4 \%$ \\
\hline in education & $36 \%$ & $34 \%$ & $44 \%$ & $35 \%$ \\
\hline & & Women & & \\
\hline & Bulgaria & Hungary & Poland & Romania \\
\hline Person-months & 29333 & 26463 & 42052 & 17139 \\
\hline \multicolumn{5}{|l|}{ \% by calendar period } \\
\hline 1980-1984 & $18 \%$ & $18 \%$ & $19 \%$ & $21 \%$ \\
\hline 1985-1989 & $20 \%$ & $18 \%$ & $18 \%$ & $24 \%$ \\
\hline 1990-1994 & $21 \%$ & $22 \%$ & $19 \%$ & $21 \%$ \\
\hline 1995-1999 & $21 \%$ & $24 \%$ & $20 \%$ & $18 \%$ \\
\hline $2000-2005$ & $20 \%$ & $18 \%$ & $24 \%$ & $16 \%$ \\
\hline \multicolumn{5}{|l|}{$\%$ by age group } \\
\hline $15-19$ & $56 \%$ & $48 \%$ & $49 \%$ & $55 \%$ \\
\hline $20-24$ & $26 \%$ & $28 \%$ & $28 \%$ & $27 \%$ \\
\hline $25-29$ & $10 \%$ & $11 \%$ & $11 \%$ & $10 \%$ \\
\hline $30-34$ & $5 \%$ & $7 \%$ & $7 \%$ & $5 \%$ \\
\hline $35-39$ & $4 \%$ & $6 \%$ & $6 \%$ & $4 \%$ \\
\hline \multicolumn{5}{|c|}{$\%$ by parity/pregnancy status } \\
\hline childless not pregnant & $94 \%$ & $86 \%$ & $93 \%$ & $95 \%$ \\
\hline childless pregnant & $0.6 \%$ & $0.8 \%$ & $1.1 \%$ & $0.5 \%$ \\
\hline mother & $6 \%$ & $13 \%$ & $6 \%$ & $4 \%$ \\
\hline \multicolumn{5}{|l|}{$\%$ by education } \\
\hline low & $10 \%$ & $11 \%$ & $5 \%$ & $17 \%$ \\
\hline middle & $25 \%$ & $33 \%$ & $30 \%$ & $29 \%$ \\
\hline high & $9 \%$ & $8 \%$ & $6 \%$ & $5 \%$ \\
\hline in education & $56 \%$ & $48 \%$ & $59 \%$ & $49 \%$ \\
\hline
\end{tabular}

